\title{
Interview with Ms. Lefosa, Director of the Lesotho Bureau of Statistics
}

\author{
Muriel Dow \\ E-mail: murielmdow@gmail.com
}

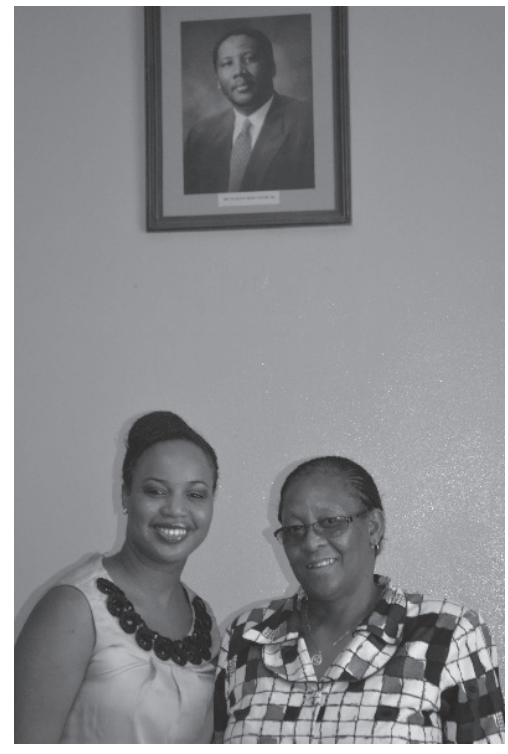

Ms. Lefosa is the Director of the Lesotho Bureau of Statistics. During her tenure here, she has transformed it from a small statistical office to a full-fledged statistical bureau. She has made outstanding contributions towards the national statistical system in her country including the Southern African Development Community (SADC) Strategy for Development of Statistics and the Strategy for Harmonization of Statistics. The interview also touches on her involvement with the design of the National Strategy for the Development of Statistics, a platform for coordination of the entire national statistical system. In the interview, Ms. Lefosa talks about the Continuous Multipurpose Survey. This survey provides data both at the national, regional and international levels. Ms. Lefosa has been a strong ad- vocate for Lesotho's adoption of the African Charter on Statistics. She is an outstanding leader in the field of international statistics, working to bring investments, financial wealth and empowerment to her country and the African continent through production of high quality statistics on the population, businesses and the environment.

Interviewer: How did you get involved in statistics? Was there any one person that influenced you to get involved in the social sciences and statistics? Please also tell us a little bit about your educational background, the places that you worked and where you were able to apply the knowledge that you gained.

I was first introduced to a course in statistics during my social science studies at the National University of Lesotho (NUL). At that time, I found statistics to be hard and I was not very keen on taking the course. It was something we had to do to pass a common core of classes the first year. However, I still had to take more statistics classes in subsequent years. But I did not feel the need to know more statistics till I joined the field of statisticians. I first became employed within the government as an economic planner at the Ministry of Central Planning (that is what it was called at the time). I was a desk officer, with the responsibility of coordinating several line ministries, their plans and their projects. Most of the government's projects needed statistics in order to be well implemented. And that is when I regretted my distaste of statistics at the university. It is also when I was forced to really work with statistics in most of the work that I was doing.

We had to review or evaluate project proposals from the ministries. You would find that an item on the eval- 
uation checklist was to check the validity of the statistics being used. That is when I gained momentum in really appreciating the importance of statistics. As a desk officer you have to participate in any project that is ongoing. You also have to participate in the evaluation of that project, particularly the post-evaluation process. And that is when you have to apply your statistics. That is when you have to see "the then" and "the now," or the before and the after impact of that project that you have been coordinating for a line ministry. I think that is where most of the influence really came about. So I think basically, that's when I appreciated the importance of statisticians, as people, as professionals.

Interviewer: And the evaluative work that they were doing.

Yes.

Interviewer: From there, can you discuss how you moved on to study at the University of Bradford to get a Master's Degree in Development Economics? What lead you to pursue your education there? How were you influenced to move in that direction?

You are hired based on your basic educational degree. As you work and become a professional worker, you realize at some point that there are certain limitations. You want to broaden your scope, you want to be more focused. Development Economics was one of the courses that really zoned in on the many little things that I had been doing as a desk officer and as a planner.

Interviewer: Next, you worked at the Ministry of Development and Planning. Can you talk about some of your work there, how you learned to plan, and to use statistics in your planning efforts?

When I was a desk officer for several ministries, I was a desk officer for the Ministry of Rural Development and Agriculture and the Secretariat itself. We had to plan for the projects and the programs within that sector. It was a time when there were several donors in the country, and for every donor there were several reporting formats for financial reports and fiscal reports. We had to do a lot of fiscal monitoring. We had to travel all over the country to go and monitor the implementation of the projects. Most of the projects particularly in the rural development sector were rural based. They were trying to empower the rural women.

I was also a desk officer for the Ministry of Gender. At that time, it was called the Ministry of Women's Affairs. At the Ministry, you would often start from nowhere with a grant perhaps provided through the
United Nations Development Program (UNDP) or from the Dutch, or whomever. Starting from nowhere, we would mobilize the women, make them aware of the possibility of a grant. In order to get the grant, they might have to form themselves into cooperatives. For instance, they may have to form a committee; they may have to identify what programs could benefit the whole community or their village, and so forth. Once that was done, that small grant would be transferred to a district bank, where there would be a project coordinator. The project coordinator would help with activities such as vegetable gardening, or other cottage industries. Our role would be to once a month go to those communities and observe their interactions and listen to their complaints or their challenges and try to assist in facilitating the whole effort.

At the end of a project, let's say a three year project, we would look at the impact. We would recognize that we came to a community that started out knowing nothing. Before the project, the community did not have services such as a post office, or a place where they could buy seeds for their vegetable garden. They had no idea. In the end, even if the project did not leave them in riches, it would have opened their minds. They would now be able to appreciate the importance of coming together, having a community, having some committees and organizing themselves.

Interviewer: Let us talk a little bit more about Development Economics.

I think coming from a third world country and having experienced some of the challenges as a desk officer, as somebody working with the grassroots at the time, the course or the program in Development Economics gives you a much broader perspective. For instance, I remember how I could relate to the examples in the literature. Take the economist Anne Krieger. She wrote a book in Development Economics. In the book, a story is told, I don't know if it fictional or real. Anyway, the story describes how the author was traveling with a delegation from the United Nations (UN) in a rural area of Bangladesh. They saw a group of people by the roadside. As they came closer to them, they were already talking about them. "They are sitting down. They are not doing anything. What are the economies of scale here? Look at them." The group asked the workers what they were doing and they said, "Nothing. We are working in the field here. When will independence be over?" What the workers meant was that there was an era before independence and things were as bad then as they were now. They were promised that 
things would be much better than what they were. The workers did not see any difference, so they wanted the era to end and perhaps go to the next era where things will be much more easy. So that is some of the lessons you learn when you study Development Economics at the University. You can relate them to your situation back home.

Interviewer: In 2005, you became the Director of the Bureau of Statistics (BoS). How did that come about?

Before I was transferred, I was working in the Ministry of Finance and Development Planning and I was Director in the Department of Manpower and Population. I was interacting frequently with the BoS. When there was a vacancy at the BoS, instead of advertising it, the government decided to transfer me into the position. I came in 2005. The Census was going to be in 2006. The Minister and the Principal Secretary (PS) who transferred me here said to go and make things right there, and go and run with the Census. "You either swim or drown." So I had only six months between September and April to prepare for the Census?

Interviewer comment for clarity: Now, in your previous job you said that you were Director of Planning?

Yes, Director of Planning in the Department of Manpower and Population. I was implementing the International Conference on Population (ICP) and Development Program of Action. I was looking at all the demographic concepts that fall in the category of population studies: migration, fertility, maternal mortality, child mortality. You name it. All the demographic concepts were covered.

Interviewer comment for clarity: So your work there was noticed and that is what lead you to the BoS.

Interviewer: You played a role in the first Poverty Reduction Papers of Lesotho. Can you talk about what your role was in the production of those papers? Also, could you discuss the purpose of those papers and how your work contributed to the $\mathrm{Na}$ tional Development Plan and the Vision 2020.

The Poverty Reduction Papers project came about because the International Monetary Fund (IMF) and the World Bank said enough with dishing out grants and assistance to countries without them participating. This is how the project came about. It was highly participatory. We had to consult with the community, with all levels of the communities, the non-governmental organizations through their umbrella body, the Lesotho Council of Non-Governmental Organizations (NGOs), the community based organizations, academia, etc. I had a specific chapter that I was writing, the Economics Chapter, and it was that chapter that led Lesotho to qualify for the grants that were being provided by the IMF. The IMF enhanced the assistance that came to the country.

Interviewer: What did you learn from working on those papers?

I think it provided us with much, more, more information. In fact, that is why we have the BoS, to get more information, to get data, to get statistics. While, I was writing this paper, I needed information on the Gross Domestic Product (GDP) for the chapter that had been assigned to me. I needed information on the inflation, on this and that, the unemployment rate, all the indicators that can provide a proper socioeconomic picture of the country. Yes, I learned a lot, really.

Interviewer: The papers contributed to the $\mathrm{Na}$ tional Development Plan of Lesotho and Vision 2020. Can you talk a little bit about Vision 2020?

All along we had been doing short term plans. The main role of the Ministry of Development Planning was to come up with 5-year-development plans. After the first 5-year-development plan, you would have another 5-year-development plan. When the Vision 2020 was introduced, it was saying, let's have a broader vision, let us look beyond five years as a country, let us have a broader vision. The plans, the five year or the three year development plans, whichever one you wanted, could be implementing based on that bigger vision. With the Vision 2020, we could focus on where the country would like to see itself in twenty years.

Interviewer: What are some of the challenges you have faced at the BoS? Have you attempted to restructure anything?

When I got to the BoS, I found first of all a team of very highly qualified statisticians. I found a team of people who knew what they should be doing. But also, a team of people who were highly demoralized. I think that the budget, the budget for the BoS, when I came here, was something like 14 million (1.4 million USD) in our local currency, of which 9 million (USD $\$ 900,000$ ) was for salaries. It was very depressing.

I looked at what was being produced and found that there was so much more that could be done, but with 
the limited budget it was not possible. It was a frustration. The following year our budget was increased to 18 million, but our salaries were still at 9 point something. In subsequent years, the budget grew and now we are at 46 million. That is how we have grown.

In terms of the infrastructure, previously, we only had one office building for the BoS. That is how it was, and we were cramped. At the district level, statistics offices were usually given the back room of some big office that otherwise could be used as a storage room. They just gave them one room within the district government offices. They were to collect vital statistics from the district; birth and death registration were done there; they were expected to collect agricultural statistics; and they were expected to collect social statistics in those small offices.

Those were some of the bigger challenges. The IT infrastructure was also very backwards, with outdated PCs. The organizational structure of BoS was also a challenge. There was only one director, and that is still how it is. Under that director, there were just three chief statisticians (for the country), and one chief statistician was responsible for quite a number of programs and products, like surveys. You would find that when you were in meetings, you would try to follow up on and ask, "So how far are you with your X number of surveys?" It was too much for one person; too easy to lose track of what has been happening with everything and everywhere. We tried to restructure and create new positions without increasing the budget.

Unfortunately, this was a time when the government was not entertaining creation of new positions. The government wanted to cut back on wages, a condition imposed by the IMF. So we tried to look at where we had redundancy in positions. We looked at positions that could be built into senior positions. We worked with our Human Resources Department (HR). I had a vision and I would tell our HR staff person how I thought it could be achieved by dividing departments. We now have seven chief statisticians.

\section{Interviewer follow-up question: and the original} divisions were?

We had a chief statistician who was responsible for the Field Division. Field Division was responsible for all our district offices and also the survey methodologies. Survey methodology, cartography, and GIS were in one division.

We had the Economics Statistics Division. This division had the national accounts, enterprises, surveys, foreign trade statistics, and the consumer price index all under one chief.
We had the Agricultural Statistics Division that housed agriculture, including crops, livestock, environment and energy statistics- all under one chief.

We had the Population Statistics Division. Previously, it was called the Demography Division. This Division was responsible for socioeconomic statistics, like labor statistics, crime statistics, education statistics, health statics, gender statistics, vital statistics and all the social statistics, all under one chief.

We also had somebody responsible for IT. That was all. Interviewer Follow-up Question: So you added
more chief statisticians to cover more ground.

We divided, for instance, the Agriculture Division. We separated out the environment, energy, biodiversity, and climate change to form one division. Agriculture became its own division. Each division had a separate Chief Statistician.

We divided the Field Division. We split out Survey Methodology, GIS, and Cartography. They have different chiefs.

We divided Population or Demography. We have Population Statistics that is now handling health statistics, gender statistics, and the Population \& Housing Census. Then we have Social Economic Statistics. That is what we did.

Interviewer: In summary, you divided up the departments, you added more chief statisticians, and you tried to level out the workload between different people in charge of different areas of statistics. Next, let us talk about how you facilitated the introduction of the Continuous Multipurpose Survey (CMS) and why you brought this new survey into Lesotho. What did it do for the country as a whole and how did it make your life easier?

When I first took office, we were often inundated with requests to conduct more surveys because we needed indicators. Instead of conducting many surveys, we proposed just one survey. The survey should be an ongoing survey, a platform to which you could attach different modules. I had come across a report prepared for my former boss by a consultant. The report focused on the Household Budget Survey. The consultant was either a supervisor on the survey or responsible for running it. The report stated that the survey was very expensive and only conducted once every five years. During that time period much would be happening in the economy which was not captured in the survey. It was the recommendation that data be col- 
lected differently. A continuous multipurpose survey was proposed.

A continuous survey can capture seasonal variations in terms of employment, unemployment, consumption, and expenditure at the household level. Furthermore, the continuous or ongoing survey can also form a platform for other surveys. Other surveys can upload their modules to this ongoing survey. A module can run for just one year or for just two quarters, one first quarter, and one second quarter. Instead of running into the problems of collecting all the data all the time, we would be asking specific questions occasionally.

Another challenge, I also noticed in the beginning, was that donors would propose surveys to collect data on very specific indicators. There were too many surveys being proposed.

Interviewer follow-up question: Can you give us an example of new indicators that were proposed to be added to a survey?

It could be an interest in collecting data on child welfare.

Interviewer follow-up question: Can you give us example of previous donors for the survey?

We have worked with the Millennium Challenge Corporation, the MCA (Millennium Challenge Account-Lesotho). When the MCA first came to Lesotho, they said that they needed baseline data for their indicators. They needed base line indicators in order to monitor and evaluate impacts of their programs in the country. They proposed we do a survey to collect the needed data. Instead we offered to work with them to add all their indicators to the CMS.

Another example comes from the water sector. In the government, the water sector is under the general budget support. A lot of money was available to be allocated to the water sector under the condition that there would be improvements in the existent indicators. Most of the data submitted by the water sector to the donors were not acceptable. The data for example would show that if a standpipe was put in, it would serve a community of 500,000 people. That would be interpreted to indicate that 500,000 people had access to clean drinking water. Our data showed a different story. It was decided that we should work together. We offered to design questions that could be mounted on our CMS. It worked. We got the information so that the water sector could show the donor data on access to safe drinking water. The money was allocated from the general budget support.

\section{Interviewer follow-up question: Did any other donors sponsor the CMS?}

The World Bank and UNICEF are working with us. We do not need donors to conduct the regular CMS. We have funding for that. Only if a sponsor would need us to expand our sample size or ask us to do something that would require us to incur additional cost do we ask for additional funding. Recently, the World Bank has asked us to work with them on what they call a social protection model for the Ministry of Social Development in their social assistance program. So these are some examples.

Interviewer follow-up question: How has the CMS made life easier here for you?

It has enabled us to cut down on the number of surveys. With a survey, you go door-to-door for data collection. Hopefully that goes well. You bring back the data and it is stored. Then you are in the field again with a new survey. In the past, there was never time to analyze and look at the data. There was a big backlog of unanalyzed data (from different surveys) and you know that expenditure on data collection is very high in any survey. You find that the expenditure is very high, but then you look at the expenditure against the product!

Now, the CMS has made our life easier. We are able to do our work, collect data, publish the report and move on. If there is a big survey, we still do standalone-surveys, we have not gotten rid of that, we have time now to concentrate on analyzing the data (and publish it).

Interviewer: When we talked before this interview, you told me how other countries want to come and learn from your model. What other countries have replicated what you have done here?

We have had Mozambique come. They spent a week with us and they started a CMS immediately after going back home. We have had Burkina Faso come and Mali.

Interviewer follow-up comment: So each of those three countries now have a CMS?

They have invited us to come and see how well they are doing.

Interviewer: Could you talk about your membership with the Southern African Development Community (SADC) Statistics Committee. Specifically, how that committee is responsible for the formu- 
lation of the regional strategy on the Development of Statistics and how your membership has contributed to the design process of Lesotho's own $\mathrm{Na}$ tional Strategy for the Development of Statistics?

The SADC statistics committee is responsible for providing policy direction to the SADC statistics agenda for the whole region. It is also responsible for ensuring that there are adequate data for the implementation of the SADC Regional Indicative Strategy Development Plan (RISDP). A number of projects and programs have been implemented, that have been initiated by the SADC Statistics Committee. This has improved the performance of the statistics in the region. For instance, it has improved the harmonization of statistics.

The SADC statistics committee initiated and drove the 2010 round of Population and Housing Census Agenda to encourage countries, particularly those that are emerging from the war, to undertake their Population and Housing Census, so that Africa can count. Because in the absence of all the 52 countries, not necessarily the SADC countries, if there is not enough statistics on the population how can the investors come and invest in Africa?

That was one of the main areas. We have also talked about harmonization of foreign trade statistics in an international forum. We have been able to talk in one voice as the region. We have good representation in the United Nations Statistics Commission. Using capacity building as an example, we have had training programs that were initiated by the SADC Statistics committee, that are now being used by the universities of selected countries in the region.

Turning now to the Regional Strategy on the Development of Statistics. There has never been a very comprehensive strategy for the SADC region until we started working on it. Lesotho along with Mozambique, South Africa, Malawi, and Tanzania and then the DRC were selected to work on the formulation of the strategy. I think we did a very good job. It has been approved by the SADC council and we are now in the phase of resource mobilization.

Interviewer: How has your membership of SADC contributed to the design process of Lesotho's $\mathrm{Na}$ tional Strategy for the Development of Statistics $(N S D S)$ ?

As part of the bigger picture, this is an African initiative. It is one of the Marrakesh Action Plans for statistics, where countries undertook to do certain things. In fact, the NSDS was supposed to be completed by 2006, but because in 2006 Lesotho was undertaking a Census we requested that we be given an extension. Immediately after completing the Census we embarked on the formulation of the NSDS. It was also quite consultative in nature because we had to consult with ministries, departments, and agencies and look into their statistical capacities. It has been a very comprehensive exercise itself indeed. The design of NSDS commenced in 2006 and was completed in 2009. It covers the years $2006 / 07$ to $2015 / 16$.

Interviewer comment: I can see that the BoS has to touch base with all of the other ministries within the country, because you are collecting statistics within the country.

The Statistics Act places us at the center of coordination of the National Statistics System. We have been mandated by the Act to be the only agency responsible for the production of official statistics, even for the departments and agencies of our ministries that are working and producing administrative statistics. This is why we will be producing educational and health statistics using the administrative reports/records of those ministries, because official statistics will only come from us.

Interviewer: What are some of the biggest challenges that you have faced in the past and are facing today within the country and/or the problems that the region is facing with statistics?

There are many challenges associated with the mandate of coordinating the National Statistics System. There is a high demand for statistics, but the supply is being jeopardized by many problems including high staff turn-around at the BoS. We are also within a government. We are still regarded as a division or a department within a ministry.

The Director of Statistics is not really able to move independently. You know our ambitions are higher than the perceptions that are outside. The Principle Secretary (PS) may not have the dream that we have, because of a lack of understanding of the importance of statistics or other bureaucratic considerations that he might have. This has really slowed down the pace. Most of the achievements that we managed to realize, have been achieved through the drive that we did. It also depended on your PS at the time. If you have a PS who is supportive and understands, you move fast. But if another PS comes in who is less enthusiastic, then you see the slow pace. That is when now you start losing staff; the statisticians want to work, they 
want to produce the figures. They do not want to be told to postpone, to defer, to cancel activities, because that demoralizes them. This has been one of the major challenges that we are now facing today. We are trying to overcome this challenge by negotiating for semiautonomous status.

Interviewer: Is there anything you want to mention about the African community and statistics?

Internationally, we have adopted the UN fundamental principles of official statistics. We have really tried very hard to confine ourselves to those fundamental principles, because they talk of quality, they talk of integrity of statistics, reliability of statistics, confidentiality, issues of statistics, and response burden-you should not overburden your respondents. Those are the principles that we have embraced. We have also embraced coming out to Africa, the Africa Charter of Statistics. I think that we are one of the few countries in Africa that have signed that charter and we have already deposited our signature to the UN Economic Commission in Africa in Addis-Ababa.

We have also really tried to embrace the statistical harmonization program. So internationally and regionally, we are part of the SADC statistics of sisters and brothers.

Internationally, we have participated in the International Comparison Program, the ICP Program (2005 and 2011 rounds) funded by the African Development Bank (AFDB). It is a global program that covered 199 economies from all regions of the world. In addition to the Consumer Price Indices (CPIs), the ICP requires countries to also start collecting prices of machinery and equipment, and building materials, as well as wages and salaries of workers in government and the construction industry. The ICP further requires countries to estimate GDP from the expenditure side, covering household and government consumption, gross fixed capital formation, change in inventories and net export of goods and services. We have been able to develop our own purchasing power parity, our PPPs. The results were published a few months ago whereby Nigeria has been identified as one of the highest in GDP, higher than South Africa. We see countries that are very expensive such as Mozambique and South Africa. People who want to invest can use that statistics to see where they can invest better and get better returns. We participated as Lesotho in that program.

Interviewer comment: I can see that statistics are very important in the development process. Statistics has done a lot in letting the world see where the region stands in terms of its economy, its environment.

Interviewer: What do you think the future holds for statistics in Africa? What do you see statistics doing for Africa in the future?

Statistics are meant to inform decisionmaking. If our leaders were to use statistics in their planning, there would be a lot of maximization of scarce resources, because we would now at least invest where there is a need and where there will be products, where you would see the outcome. The alternative is political decisions that are not based on any statistical realities. If there were more utilization of statistics, then I think our region or our continent would improve a lot.

Interviewer: And then to that end, what do you think the future holds for your agency, the Bureau?

I hope that the Bureau could become semi-autonomous. We are not looking to become a high-flying institution with high salaries and pensions. A high salary staff may not be productive at all, but if there could be that element of semi-autonomy, then there would be some degree of flexibility. For example, decisions made by the Ministry of Public Service are government-wide. They affect the entire government. A government-wide moratorium on creating new positions prevents BoS from growing. We are not able to grow in terms of human resources.

Interviewer follow-up comment: If you were given semi-autonomy, how do you want to see the Bureau grow?

For right now, I can say that we are not fully decentralized. We do have statisticians in all of the nine districts beyond the Central Office's capital location in Maseru. But there is just one statistician in each of those districts and the districts are big. The statistical requirements are huge for one statistician. If we can decentralize, it would mean that the quality of statistics at the district level would improve. The Bureau would grow in the sense that we would be able to place more statisticians beyond Maseru or beyond the capital. And we could stress the importance of statistics to district administrators.

Interviewer follow-up comment: So you want to see more resources for the collection of statistics, to improve the quality here.

There are still a lot of data that we are not collecting because of limited resources and a lot of statistics we are not producing. Right now we are just doing the 
Consumer Price Index. We are yet to start the Producer Price Index. I have started little by little, but I need more resources, more people, and financial support to move to that area as well. We need to show how much we spend on production, not just how much we consume. Those are some of the outstanding issues for me.

There is also a module on governance, peace and security. Most countries have started collecting information on governance, peace, and security, but we have not yet started. We have the questionnaires, we have the module, but we do not have adequate resources to embark on that one. There are a number of other areas, where we need to see ourselves getting into soon.

Interviewer comment: All in all, I think that you have done a great job, introducing new surveys, and restructuring the department, but I also see that you have a vision for going further.

Interviewer: Can you talk about the importance of Lesotho's environment to the region?

Lesotho is an enclave inside South Africa. We are affected by the environment that surrounds us and we in turn affect the environment outside Lesotho. For instance, if the emissions from Lesotho are severe we know our neighboring South Africa towns are going to be affected.

We do not have physical borders. Political instability can cause people to flee from country to country. Same goes for animals. Just as an aside, I can tell you that in a meeting this morning we were talking about the borders and wildlife. Our environment staff was making a report of the species, issues of biodiversity, etc. They were telling me a lion from South Africa has escaped from the zoo, or whatever, and it was seen in Lesotho, but they do not know where it is. It has disappeared. It is roaming somewhere. It could be anywhere. This is our situation.

When I got to the BoS, I introduced an Environment, Energy, and Statistics Division. I knew from working on the Millennium Development Goals (MDG) before I got here that Lesotho did not have any data on the environment.

Interviewer follow-up question: So you were able to introduce a survey to collect information on Lesotho's environment?

Now we can talk about topics such as energy consumption and air emissions. Our first ever report from the Division was published in 2013. We want to do a full fledged energy survey. We are trying to get funding for that. We have been talking to the EU. They have looked at our concept note. The EU wants us to expand to the Energy Sector as well. They have something like 28 million Euro for Lesotho. We told them that we cannot start anything without baseline data. We are still negotiating.

Interviewer: Thank you, M'e' Lefosa for the work that you have done in Lesotho. It has been a great accomplishment; we definitely want to share that information with the world, what's been going on within the Southern Region of Africa. Lesotho, we know, is a small country, but we can see that with that smallness something great can happen here and the work that you have done here in Lesotho has also had a great impact on other countries throughout Africa. And so we thank you, we thank you for your time and the work that you have done in Lesotho.

Ms. Lefosa was interviewed in her office in Lesotho by Muriel Dow in the fall of 2014. Kirsten West participated by telephone.

Muriel Dow is a Resident Technical Advisor at IHM-the Institute of Health Measurement Lesotho. She is currently working on producing Lesotho's first HTC (HIV testing and counseling) \& ART (antiretroviral therapy) Annual Report under the President's Emergency Plan for AIDS Relief (PEPFAR) funded grant. Her experience includes working on the US Millennium Challenge Corporation's Lesotho Health \& Water Sector Compact to coordinate monitoring and evaluation of the major activities for the project and the implementation of several nationally representative household and health center surveys. Muriel holds a PH.D. in Intercultural Communication/Graduate Certificate in International Studies from Howard University and a Graduate Certificate in Survey Design and Data Analysis from George Washington University.

Kirsten West is a demographer at the U.S. Census Bureau. Her area of expertise is population estimation and census coverage measurement. She has worked on the 1990 Post-Enumeration Survey, the 1991 Evaluation Survey, the 1991 Evaluation Survey, and the 2000 and 2010 Demographic Analysis operation. She holds a Ph.D. from the University of North Carolina at Chapel Hill. 